\title{
ALTERNATIVE FUNDINGS TO IMPROVE ROAD SAFETY IN MALAYSIA
}

\author{
Md. Zarulazam Md. Eusofe ${ }^{1}$, H. Evdorides ${ }^{2}$ \\ ${ }^{1}$ Doctoral Researcher, ${ }^{2}$ Lecturer, School of Civil Engineering, College of Engineering \& Physical Sciences, University \\ of Birmingham, Edgbaston, B15 2TT, United Kingdom \\ ${ }^{1}$ zxe310@bham.ac.uk, ${ }^{2}$ H.Evdorides@bham.ac.uk
}

\begin{abstract}
Road safety is a major transport, health and social issue worldwide as an estimated 1.3 million road users are killed on the roads every year, of which $90 \%$ are in low and middle-income countries (LMIC), where $72 \%$ of the world's population lives but only half of the world's registered vehicles are owned and driven. In terms of cost, it is estimated that USD 518 billion of lost yearly has been recorded according to the World Health Organisation, WHO (2009). These poor road safety records require immediate actions to be taken in areas of management, institutional reform and funding. Malaysia is an established dynamic and progressive LMIC seeking to improve its road safety performance and until today it depends mostly on the government's revenues to finance its road safety plans. This practice however may cause burden to the government yearly budget which also need to cater for other sectors such as education, health and defence. To this end, this paper explores and critically evaluates the current situation of road safety inclusive of its funding mechanisms on a global scale as well as in Malaysia. In an effort to improve the situation, the paper aims at analysing the effectiveness of funding mechanism in enhancing road safety. A number of examples of successful road funding mechanism worldwide are presented together with implementation issues with the view to suggest options to improve road safety management and financing at both national and local level in Malaysia.
\end{abstract}

Index terms: Road safety funding, Road safety in Malaysia, Second generation road fund.

\section{INTRODUCTION}

As of 2011, World Health Organisation (WHO) reported that injuries arising from road traffic were ranked as ninth in the world that led to death. The poorly practiced road safety measures require urgent improvement, where the specific areas that can be looked into are the areas of management, institutional reform and funding. Globally, the issue of poor road safety impacts the social and health factors, because it directly affects the critical trade and economic sectors. As a result, recently road safety became a priority for the central governments and all the associated governing agencies. Apart from that, the significant economic growth in the last decade altered the lifestyle of ordinary citizens, hence resulted in increased personal vehicle and public transportation usages. Since the number of vehicles has increased, the reckless driving attitudes and poor driving skills have been amplified, and resulted in increased road accidents and proportionally as well as the death rates and uncounted serious fatalities on road[8].

In order to overcome the serious road safety malfunction, various measures have been introduced by most governments, namely legislative and institutional frameworks on improving the road safety management. Additionally, many governmental or private agencies were initiated to solve the road safety malfunction[13]. However, the agencies were not effective in reducing the road safety incidents, which can be observed from the increasing road carnage.
In 2009, WHO predicted that LMICsproduced increasing fatality rates that are prone from road accidents (low-income countries resulted in 21.5 per every 100,000 population, while middle-income countries resulted in 19.5 per every 100,000 population). In the case first world countries, the fatality rate due to road traffic resulted in approximately 10.3 per every 100,000 population. As of 2009 , the WHO presumes, "Over $90 \%$ of the world's fatalities on the roads occur in LMIC, which have only $48 \%$ of the world's registered vehicles."

Accidents related to road traffic was failed to be reduced by LMICs, simply because the institutional road safety management was poorly conducted by LMICs. The poor conduct of LMIC was brought to limelight by Road Traffic Injury Prevention 2004 within the World Report[4]. As a solution, several approaches were proposed by the World Bank, including the supply of financial and human resources to support the increase of road safety.However, it was found that without supplying actual funding and required skills, the proposed road safety structures and relative processes by government are unproductive, and eventually fails to provide the necessary impact.

\section{ROAD SAFETY SCENARIOIN MALAYSIA}

Malaysia, a country located in the South East Asia region, is a well-established and dynamic LMIC. After 1957, which is when Malaysia attained her independence, massive economic growth was demonstrated by Malaysia in the areas of population, industrialization, and motorization. The 
average population growth of Malaysia demonstrated a surging pattern, where the population was 24.7 million in 2002 and increased to 29.4 million in 2012, with an incremental rate of $2.5 \%$ (Department of Statistics Malaysia, 2013). Similar to other developing nations, Malaysia demonstrated significant economic growth and supported new economic activities, including construction and transportation industries. Figure 1 illustrates the total registered motor vehicles within Malaysia, where an increasing trend can be observed from 6.18 million in 1994 to 22.7 million in 2012 (Department of Road Transport Malaysia, 2013).

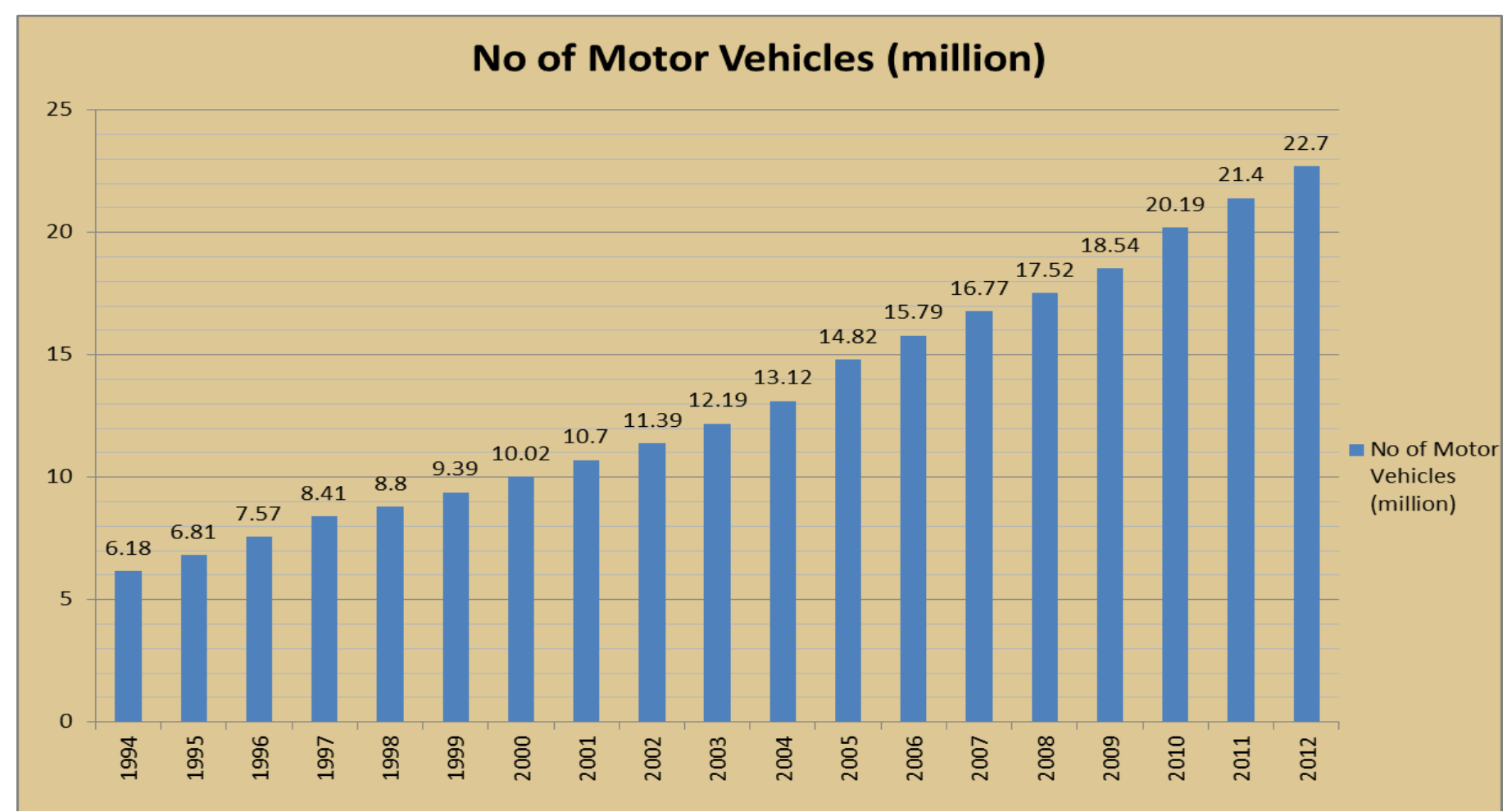

Fig-1: Total number of motor vehicles in Malaysia (1994-2012) (Source: Department of Road Transport Malaysia, 2013)

As indicated earlier, one of the impact of having a growing economy is the increasing number of vehicles used, which incidentally leads to a higher probability for Malaysians to get into an accident. Therefore, even though government accommodated the rapid development, there is concurrent increase in the number of road traffic accidents. This can be observed through the total road fatalities rate at 250,429 in the year of 2000 that increased to 414,421 in the year of
2010 (Malaysia Institute of Road Safety (MIROS), 2013). However, in order to address the growth in vehicle usage, Malaysian government introduced new facilities and infrastructures, namely construction of relevant roads and highways to solve the congestions As of the year of 2013, new highways, federal and state roads, and private roads that span up to approximately $180,000 \mathrm{~km}$ had been constructed in Malaysia, as shown in Table 1.

Table-1: Malaysia road network

\begin{tabular}{|c|c|c|c|c|}
\hline ROAD CLASSIFICATION & $\begin{array}{c}\text { MAIN FEDERAL } \\
\text { ROAD } \\
\text { (until 2011) }\end{array}$ & $\begin{array}{c}\text { FELDA ROAD/ } \\
\text { ENTRANCE TO } \\
\text { INDUSTRIAL/ } \\
\text { INSTITUTION } \\
\text { (until 2011) }\end{array}$ & $\begin{array}{c}\text { HIGHWAY } \\
\text { (until 2013) }\end{array}$ & $\begin{array}{c}\text { STATE ROAD } \\
\text { (until 2011) }\end{array}$ \\
\hline ROAD LENGTH (KM) & $11,236.54$ & $5,970.47$ & $1,775.38$ & $163,061.2$ \\
\hline AUTHORITY & \multicolumn{3}{|c|}{ MINISTRY OF WORKS } & $\begin{array}{c}\text { MINISTRY OF RURAL } \\
\text { AND REGIONAL } \\
\text { DEVELOPMENT/MOW }\end{array}$ \\
\hline $\begin{array}{c}\text { MAINTENANCE AND } \\
\text { MONITORING BY }\end{array}$ & Public Work Department & $\begin{array}{c}\text { Malaysia Highway } \\
\text { Authority \& Concession } \\
\text { Company }\end{array}$ & $\begin{array}{c}\text { STATE PWD/ LOCAL } \\
\text { AUTHORITY }\end{array}$ \\
\hline
\end{tabular}


(Source: Highway Planning Unit, Ministry of Works \& Malaysia Highway Authority, 2013)

According to the estimation of MIROS, the failure of Malaysian government in introducing a solution on enhancing the road safety by the year of 2020 will result in more than 10,000 road fatalities. The estimated figure of fatalities is alarming, hence requires immediate strategic efforts that are applicable before the situation becomes critical

During the 80 s era, campaigns related to road safety were conducted by various agencies as part of their main tasks as allowed by law. Additionally, the government itself applied some immediate solutions to solve the significantly increasing road accidents. One of the important measure introduced by Malaysian government was the formation of the multi sectorial non-statutory advisory board, also known as the Road Safety Council, which directly helped the government to reduce the road fatalities

After the establishment of the Road Safety Department, Malaysian government introduced the first Road Safety Plan of Malaysia (RSPM) in the year of 2006 that covers from 2006 to 2010. The framework of RSPM unveils the road safety implementation approaches through the four E's, namely engineering, education, enforcement and environment, while supplementary items include coordination, funding and mechanisms that operate based on the areas prioritized by the plan (RSD 2006).If this plan was achieved, the government targeted the road accident to be reduced by the year of 2010, as illustrated in Box 1 .

[1]. Reduce the number of road deaths per 10,000 registered vehicles by $52.4 \%$ from 4.2 in 2005 to 2.0 in 2010

[2]. 10 deaths per 100,000 population as compared to the current 23 deaths per 100,000 population and

[3]. 10 deaths per 1.0 billion vehicle kilometre travelled compared to the current 18 deaths per 1.0 billion vehicle kilometre travelled

Box-1: Target for Road Safety Plan 2006-2010(Source: Road Safety Department of Malaysia, 2006)

The outcome of the plan measured in the year of 2010 is shown inTable 2. It is clear that the goals set out in RSPM 2006 to 2010 were not completely achieved, however some degree of improvements related to road safety can be observed during the RSPM. As reported by RSD, the key reason that the plan was not achieved is related to the implementation delay of some important initiatives.

Table-2: The RSPM 2006-2010- Targets and Outcomes

\begin{tabular}{|l|l|l|l|l|}
\hline Road Fatalities Indicator & $\begin{array}{l}\text { Road Fatalities } \\
2006\end{array}$ & $\begin{array}{l}\text { Road Fatalities Target } \\
2010\end{array}$ & $\begin{array}{l}\text { Road Fatalities } \\
2010\end{array}$ \\
\hline Per 10,000 Registered Vehicles & 4.0 & 2.0 & 3.4 \\
\hline Per 100,000 Population & 23.6 & 10.0 & 23.8 \\
\hline Per Billion Vehicle Kilometre Travelled (VKT) & 18.9 & 10.0 & 17.3 \\
\hline
\end{tabular}

(Source: Road Safety Department of Malaysia, 2011)

\section{THE PRESENT STATE OF FUNDING FOR ROAD SAFETY IN MALAYSIA}

The WHO published an article titled "The World Report on Road Traffic Injury Prevention"in 2004, which provided six important measures that have to be implemented by a country to improve the respective level of road safety (see Box 2).Among the recommendations, financial and technical resources are important to effectively improve the level of road safety. However, the WHO realized that when manpower and financial resources are limited in an LMIC, then practicing the recommendations will be complex. This finding is similar to the outcome ofBliss and Breen's (2009) research, whereby agreed that financial and manpower allocations were important to effectively implement measures to improve a road safety management system.

Box-2: The World Report Recommendations

[1]. Identify a lead agency in government to guide the national road traffic safety effort

[2]. Assess the problem, policies and institutional settings relating to road traffic injury and the capacity for road traffic injury prevention in each country

[3]. Prepare a national road safety strategy and plan of action

[4]. Allocate financial and human resources to address the problem

[5]. Implement specific actions to prevent road traffic crashes, minimize injuries and their consequences and evaluate the impact of these actions

[6]. Support the development of national capacity and international cooperation (Source: The World Report on Road Traffic Injury Prevention, 2004) 
In any country, without sufficient amount and sustainable mode of funding, the road safety improvement would not be possible. As described by Downing (2004), road safety plans had been failed to be implemented bymany countries due to lack of funding. Such phenomenon is worrying and further complicates the implementation of road safety processes, and as a result sustains the fatalities occurred due to road accidents.Heggie (1999) indicated thateconomic sector that is related to road grows at face pace, hence such sector relying solely on government funding would not be efficient. Some of the key factors that reduce the government fund allocation for road are as follows:

[1]. Defence, health and education sectors require more funding for strategic reasons;

[2]. Higher tax cannot be imposed on tax payers as it will burden the common citizens;

[3]. Delay in road maintenance will have minimal impact; and

[4]. The costs pertaining to road construction and maintenance increases on yearly basis, hence cannot be completely supported by the government.

To successfully achieve every road safety related initiatives, the related budget has to be sufficiently and logically scaled. This statement can be supported by the finding of Bishai et al., (2003), which reveals that road safety related investment is correlated to the envisaged positive aspects. Furthermore, the case studies conducted in Uganda and Pakistan, which is two different LMICs, demonstrated that road accidents can be drastically reduced relative to the increasing investment on improving road safety infrastructure.

It is important to state that the situation is similar in Malaysia, where road construction and infrastructure improvement budgets are sponsored by the government through annual allocation. Although annual budget includes both careful planning and sufficient fund, but considering the current road safety requirement with aggressive initiatives and public awareness campaigns, over time the budget would be insufficient and results in requiring additional fund. However, it is true that theoretically funds from other sectors can be channeled into road safety initiatives, but practically it will be complex to reroute the funds from strategic sectors, namely health, education, and defence.

\section{SOURCES OF ROAD SAFETY FUNDING}

Some of the major sources for road safety funding arethe general tax revenues, which are considered part of the government budget;specific taxes, one of the example is the fines related to traffic offencethatare allocated to spend on road safety;levies arising from insurance premiums;private industries sponsorships; and contribution from road user charges, also known as road funds.

Although there are various sources of funding on road safety, only a number of countries realize the importance of investing on road safety. Some these countries are The United Kingdom (UK), which carried out a case study on the road safety expenses and costs, followed by New Zealand that prioritized the monitoring of the funding sources for road safety improvement. Furthermore, the government allocated funding is also utilized for road repairing rather than improving road safety, which effectively defeats the entire purpose of the funding. However, there are also LICs that allocate funds for corrective mechanisms programs, which can be observed from National Road Safety Councils (NRSCs) that receives support directly from government. But, again dedicated funding for road safety is not widely practiced.

\subsection{Government Budget Through General Tax}

\section{Revenues}

In the eye of the public, any tasks related to road safetyare perceived as the obligation of public sector. Any development on road safety will be a collective budgeted across the sectors that are involved, namely the transport ministry, state and central governments road departments, medical sector and public safety sector. But, it is important to state that there won't be a clear number on the exact funding required by individual sector. The findings of a study conducted by the government of UK revealed that private sector consumes $57 \%$ of the allocated fund on road safety, where the spending is on driver training and testing, and vehicle inspection[1]. In the public sector, the expenditure related to the ambulance and hospital services is $50 \%$, while police division spends about $27 \%$. The heavy lobbying from the health sector forced a major development on the road infrastructure; as a result insurance claims for health treatment in hospitals are easier now. The remaining fund of $33 \%$ is utilized by the transport ministry, the national road agency and local authorities. On the other hand, the NRSCs or the equivalent bodies usually suffer from insufficient fund due to none direct budget allocation for road safety.

\subsection{Levies Added To Insurance Premiums}

From the allocated budget, the fund also covers the accumulated levy or surcharge of the required insurance premium for road safety events. This is because insurance premiums are directly affected from road accidents due to payouts, therefore the insurance agencies provide incentives to lower accident rates. Both the public and the insurance companies must accept any additional surcharge on insurance premiums. One way of improving this scenario is by not excluding any parties from paying levy (e.g., some countries exclude government vehicles). Therefore, the money earned from imposing levy should be managed without prejudice and upkeep fairness among the participating insurance companies.

However, the complexity in implementing such a funding scheme is that LICs are having too many vehicles without licenses or insurances that can reach up to $50 \%$ of the total existing vehicles. Two problems arise from this scenario, where firstly the fund produced by the levy can be reduced, and secondly, which is a bigger issue is that the higher levy 
increases the insurance fee and directly produces more uninsured vehicles. As a solution, South Africa utilizes fuel levy scheme to generate fund for third party injury premiums. The benefit of this scheme is basically linking between the frequent road users that pays higher petrol levy, and in return contributes more towards insurance levy. The fuel levy to insurance levy scheme had been adopted and practiced by four different South African nations and being considered by Mauritiusfor implementation [1].

\subsection{Partnership/ Sponsorship}

Many private industries sponsors road safety related activities to generate positive image for good product marketability, create new line-of-businesses through demonstrations of developments, and also to provide a perception that their products are safe. Fewer road crashes and safer driving practices may also give them benefit from the lower costs associated with it. The sponsorship can be either provided directly, or in kind, or both simultaneously. Such corporate sponsors focuses on delivering four major agendas, namely road safety education and knowledge transfer, road safety awareness campaigns, enforcement campaigns, and driver training and awareness. One of the corporate members is the car manufacturers that contribute widely by providing materials and monetary investment on road safety education. On the other hand, the UK government co-financed the public transportation sector and provided more taxi services and late night buses as means of transport for intoxicated drivers. Concurrently, UK government also sponsors free non-alcoholic drinks for selected drivers.Educational and publicity of the naming, packaging, and merchandising of alcohol beverages strictly follows the code of practice. Corporate sponsorships also involve in the law enforcement sector, where polices are supported by the supplies of special vehicles and breathalysers. Additionally, the training for drivers are normally conducted by private sectors, where defensive driving lessons and occasional organizing of driving competitions are carried out to support safer driving campaign[1].

\subsection{Earmarked Taxes (First Generation Road}

\section{Funds)}

Introducing specific tax system for a specific purpose is known as earmarking. In this case, earmarking does not come from government budget, therefore the allocated budget for all sectors will be reduced to contribute towards earmarking scheme. Therefore, both finance ministries and IMF are not warmed up to the idea of earmarking [14], and will only agree if the additional fund required comes from the road users and consequently neutralizes the scheme, because then the budget from other sectors will stay unchanged First generation road funds adopted this earmarking scheme. The money generated from traffic tickets is occasionally used for earmarking purpose, where the additional money is used to fund the activities of traffic law enforcement. However, the earmarking scheme based on first generation reduces the profit that supposedly returned to government, thus not actually neutralising the budget. Furthermore, improving the law enforcement will result in better road usage and will directly reduce the traffic offense related incomes. Therefore, applying earmarking methods on traffic related offenses must be carefully considered by taking into account the potential income and profit[5].

By recognizing all the drawbacks of earmarking scheme on traffic related offenses resulted in the scheme not being widely applied, with Vietnam being the only exceptional case that completely applies the earmarking scheme for road safety funding. Semi-earmarking scheme is applied in Malaysia and the Philippines, where the payment received for traffic related offenses are partly absorbed by the police, while Ethiopia completely stopped earmarking scheme for traffic related offenses[1]. One of the recent achievement via earmarking scheme is the installation of number of red light enforcement and speed control cameras to assure that drivers follow the procedures of traffic signals. These particular cameras introduced new measures in curbing traffic offenders and generate additional revenue that is used for road safety improvement. Apart from that, Western Australia government moves one third of the red light and speed traps fines into the Road Trauma Trust Fund. In the case of UK, speed traps are being introduced and the revenue generated will be directed towards additional speed traps installations at specific areas. On the other hand, some states in the United States of America (USA) tunnel part of the traffic fines into specific trainings on law enforcement, while additional surcharges are introduced for high risk movement violations in the state of Mississippi and revenue generated will be used for emergency medical care. The final goal of the implementation of various measures is to directly decrease the traffic fines in future.

\subsection{Road Funds (Second Generation Road Funds)}

After the year of 1990, a general platform for road funds were built to generate a long term plan that successfully improves road safety measures[14]. Part of the long term plan is to connect roads into business districts and incorporate a fee-for-service basis. These specific roads collect fees from users, and the fees are used toward improving the road infrastructure and safety aspects (New Zealand is a prime example in collecting the road fund, subsequently emerged as 'good' practice)[1]. A board that comprise of representatives of road users and business owners usually manages the road fund. The road funds are also collected through levying the fuel price, fee related to vehicle registration, vehicle license fees and direct road user charges (e.g., tolls and weight-distance fees), and the levy category varies according to the country.

Some of the collected funds are also channeled as subsidies for road safety aspects. Generally, the road safety subsidies and spendings are decided by a central board. Wherever a board is applicable, the local road and transport agencies that require the road fund needs to prepare supporting documents with a well-prepared road safety programs. 
Some road funds directly allocate a specific budget on road safety to provide continuous support. Recently, the Ethiopian Road Fund Board reported that up to $3 \%$ of the road fund could be freely direct towards the road safety[15]. Considering other nations, Ghana has already created a road fund to initiate a monetary source to maintain the road safety support the NRSC, and data collection approach for major road crashes.

\subsection{Second Generation Of Road Funds As A}

\section{Solution To Road Safety}

Compared to the earmarking scheme of the first generation road funds, the second generation earmarking scheme has been improved with additional legal frameworks. The improvements comprise of efficient management of the collected funds and proper accountability for the government and the general public. Benmaamar (2006) reported on the second generation road funds with the following statements, "Thus governed by specific legislation which sets out the roles and responsibilities of a representative management board to oversee operations and a secretariat to manage the business of the road fund on a day-to-day basis. "The legislation was primarily introduced to initiate an institution that controls the resources related to the scheme and assure that the road funds are utilised for the right purpose. Additionally, Heggie and Vickers (1998) created a framework for second generation funds with possibility of being subjected to change:

$>$ precise legal framework that covers clear regulations, rules, with a separate administrator for road fund;

$>\quad$ an agency that specifically purchase services related to road maintenance and does not provide services related to road maintenance;

$>$ an administrative structure that is viable financially, and both efficient and lean;

$>$ regular and increased financial and technical audits; and

$>$ generate more revenue from charges related to road use and store the fund in a bank account dedicated for road fund bank.

The second generation road fund scheme is being adopted by most developing countries to solve the lack of funding issue on road maintenance and the inefficient system that carry out the road maintenance tasks. As specified earlier, the second generation scheme receives fund from fuel levies, while the management of the fund is the responsible of the board that upholds the interest of general public. However, according toGwilliam and Kumar (2003), most economists did not agree with the idea of second generation funds, and the exact reported statement was that "Macroeconomists often oppose such funds, arguing that this earmarking of revenue reduces fiscal flexibility".

On the other hand, some researchers reported that such road fund schemes should be an intermediate solution before forming a full scale commercialized road maintenance system, therefore it is subject to sunset provisions. Gwilliam and Kumar (2003) also stated that prior to deciding on the usage of second generation scheme, the impact of such scheme on the resource allocation, rent seeking and operational efficiency should be thoroughly analysed.

However, it is also possible to apply the second generation road funds in various approaches to solve road safety problems. Furthermore, the application of second generation road funds can be diverse due to the increased accountability and improved management prospect compared to the first generation roads funds [17]. As reported by Transportation \& Development Institute (American Society of Civil Engineers) and American Society of Civil Engineers (2009), road safety is not widely successful because of the insufficient fund allocated for road safety improvement and as well as the poor management of the insufficient fund for road safety development. However, this is not applicable with the second generation road funds as the scheme practices efficient fund management that assures the funds are directed towards the right purpose.

From the perspective of Fan and Chan-Kang (2005), poor roads were prone to produce more road accidents compared to the good conditioned roads. Such remark reveals the idea that more road accidents can be observed in the upcoming, middle and low income countries due to the chances of having increased poor conditioned roads. In order to justify such claim, the finding ofDahdah (2008) can be taken as a reference, where it was found that road accidents were low in developed countries owing to better road infrastructures. The second generation roads funds are managed on the grounds of administrative autonomy, financial autonomy and regular auditing. The management processes are important to provide increased transparency, accountability and reporting for the fund used to perform the roadmaintenance activities, so that safer roads can be successfully achieved. Furthermore, there are also sets of rules and regulations within the second generation road funds, which provide the processes of properly utilizing the funds towards improving the road safety via various options. An additional approach taken by the second generation scheme is to improve the road infrastructure by separating the channels for the service provider and the purchaser. The purchaser is basically the road fund, while the service provider is the road agencies and relevant departments, and the separation among the purchaser and the service provider assures a smooth and quality delivery of service owing to the decreasing nature of the conflict of interest.Benmaamar (2006) remarked the following statements on the separation, "Road fund boards tend to cumulate too many conflicting responsibilities, which often include funding, planning and managing road works. In such cases, they act both as the customer for the services provided, as well as the provider of those services. This creates an obvious conflict of interest, which weakens financial discipline and compromises efforts to control costs and maintain quality".

\section{CONCLUDING DISCUSSION}

From the thorough review carried out in the proposed work, it is clear that the road safety level is at high risk, especially in the region of LMICs. This is due to the weak enforcement 
of law, loosely created legislation and legal frameworks that supposed to ensure the proper usage of the funding for road safety. The only approach of improving every aspects of the road safety management is by applying immediate and imminent changes to the areas of management, institutional reform and funding. Solving road carnage is not a straightforward process.

Furthermore, it is clear from this proposed review that funding is the ultimate bottleneck towards improving the road infrastructure to attain safer roads, where many plans were made to achieve safer roads and mostly became unsuccessful due to the lack of funding[7]. It is envisaged that by exploring and using the mechanism of second generation road funds, a sufficient and sustainable funding for road safety can be proposed in order to ensure the effectiveness of a road safety management plan such as that in Malaysia. However, this requires a systematic investigation to examine the factors that affect the implementation of second generation road funds, appropriate communication within authorities concerned, political support and a comprehensive plan to establish the funding mechanism in a sustainable manner.

\section{ACKNOWLEDGEMENTS}

The authors would like to take this opportunity to acknowledge the Government of Malaysia for the research funding, the Malaysian Highway Authority and the senior officials participates in the study for their contributions and ideas.

\section{REFERENCES}

[1]. Aeron-Thomas A, Downing AJ, Jacobs GD, Fletcher JP, Deslby T and Silcock DT (2002). A review of road safety management and practice. London: DfID.

[2]. Benmaamar, M. (2006). "Financing Of Road Maintenance In Sub-Saharan Africa Reforms and progress towards second generation road funds." Road management and Financing - RMF Series, Discussion Paper No. 6.

[3]. Bishai, D., Hyder, A. A., Ghaffar, A., Morrow, R. H., \&Kobusingye, O. (2003). Rates of public investment for road safety in developing countries: Case studies of Uganda and Pakistan. Health Policy and Planning, 18(2), 232-235.

[4]. Bliss, T., \& Breen, J. (2009). Country guidelines for the conduct of road safety management capacity reviews and the specification of lead agency reforms, investment strategies and safe system projects. World Bank Global Road Safety Facility, Washington, D.C.

[5]. Creightney C. (1993). Road User Taxation in Selected OECD Countries. Sub-Saharan Africa Transport Policy Program Working Paper No. 3. The World Bank and Economic Commission for Africa.

[6]. Dahdah, S. (2008). Modeling an infrastructure safety rating for vulnerable road users in developing countries. Ann Arbor, MI: UMI.

[7]. Downing, A. (2004). Addressing the challenge of road safety. In Public health in the Middle East and North Africa, Meeting the challenges of the twentyfirst century.

[8]. Elvik, R., Vaa, T., Erke, A., \& Sorensen, M. (Eds.). (2009). The handbook of road safety measures. Emerald Group Publishing.

[9]. Fan, S., \& Chan-Kang, C. (2005). Road development, economic growth, \& poverty reduction in China. Washington, DC: International Food Policy Research Institute.

[10]. Gwilliam, K \& Kumar, A. (2003). "How Effective Are Second-Generation Road Funds? A Preliminary Appraisal." World Bank Research Observer, 18(1), $113-128$.

[11]. Heggie, lan G. and Piers Vickers. (1998). Commercial Management and Financing of Roads. Technical paper 409, World Bank, Washington, D.C.

[12]. Heggie, I. G. (1999). Commercially managed road funds: Managing roads like a business, not like a bureaucracy. Transportation, 26(1), 87-111.

[13]. Ogden, K. W. (1996). Safer roads: A guide to road safety engineering. Aldershot: Avebury Technical.

[14]. Potter, B. H., 1997, Dedicated Road Funds: A Preliminary View on a World Bank Initiative. IMF Paper on Policy Analysis and Assessment (Fiscal Affairs Department, Washington, DC: IMF)

[15]. Transport Research Laboratory (2000), Ethiopia Road Safety Study Survey Report,Crowthorne.

[16]. Transportation \& Development Institute (American Society of Civil Engineers), \& American Society of Civil Engineers. (2009). ICCTP 2009: Critical issues in transportation system planning, development, and management. Proceedings of the Ninth International Conference of Chinese Transportation Professional: August 5-9, Harbin, China. Reston, VA: American Society of Civil Engineers.

[17]. World Bank. (2007). A decade of action in transport: An evaluation of World Bank assistance to the transport sector, 1995-2005. Washington, D.C: World Bank.

[18]. World Health Organization (Ed.). (2009). Global status report on road safety: Time for action. World Health Organization. 